International Journal of Applied Dental Sciences 2021; 7(2): 490-492

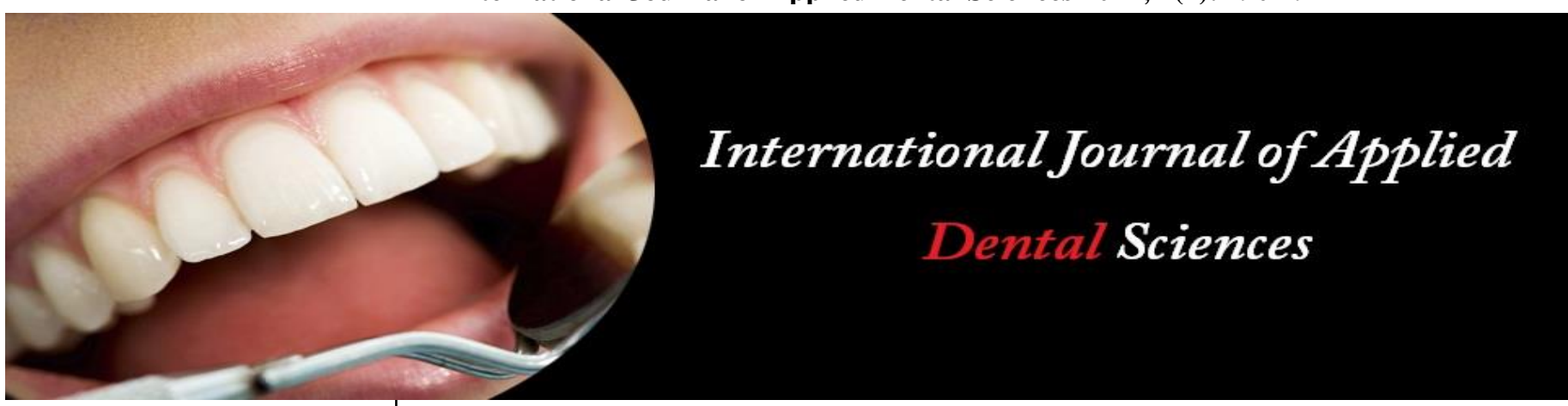

ISSN Print: 2394-7489

ISSN Online: 2394-7497

IJADS 2021; 7(2): 490-492

(C) 2021 IJADS

www.oraljournal.com

Received: 01-02-2021

Accepted: 03-03-2021

\section{S Srikanth Raju}

Asst. Professor, Dept. of

Pedodontics, Kamineni Institute

of Dental Sciences, Narketpally,

Nalgonda, Telangana, India

M Sai Divya

MDS, Consultant Pedodontist

Hyderabad, Telangana, India

Anil Kumar Maradi

Asst. Professor, Dept. of

Conservative dentistry and

Endodontics, Kamineni Institute

of Dental Sciences, Narketpally,

Nalgonda, Telangana, India

Jayyarapu Dilip

Asst. Professor, Dept. of

Prosthodontics, Kamineni

Institute of Dental Sciences,

Narketpally, Nalgonda,

Telangana, India

\section{Vidhyadhar D}

Asst. Professor, Dept. of

Prosthodontics, Kamineni

Institute of Dental Sciences,

Narketpally, Nalgonda

Telangana, India

P Gowtham

MDS, Consultant Pedodontist

Hyderabad, Telangana, India

Corresponding Author:

S Srikanth Raju

Asst. Professor, Dept. of

Pedodontics, Kamineni Institute

of Dental Sciences, Narketpally,

Nalgonda, Telangana, India

\section{Anxiety to dental procedures among adolescents in Nalgonda district, Telangana, India: A cross sectional study}

\author{
S Srikanth Raju, M Sai Divya, Anil Kumar Maradi, Jayyarapu Dilip, \\ Vidhyadhar D and P Gowtham
}

DOI: $\underline{\text { https://doi.org/10.22271/oral.2021.v7.i2h.1250 }}$

\section{Abstract}

Introduction: Dental anxiety in adolescents is often noticed and is a cause of postponement of appointments, delay in seeking dental care or even avoidance of seeking dental treatment resulting in a poor oral health-related quality of life. Even though dentistry has steer up with much advancement, because of this dental anxiety patients are not stepping in the initial phase of treatment eventually leading to more invasive procedures. This study was undertaken to know which dental procedure will provoke more anxiety in the adolescents.

Materials and Methodology: A custom-made questionnaire was prepared related to frequently done dental procedures. A total of 500 adolescents within the age group of 15-19 years were participated in the study. Filled questionnaires were collected; data was tabulated and statistically analyzed.

Results: In Group I (male), 76.4\% of adolescents were highly anxious to extraction/ surgical procedures followed by root canal treatment $(70.8 \%)$ and crown preparation with impression procedure $(64.4 \%)$. In Group II (female) $89.2 \%$ of adolescents were highly anxious to extraction/ surgical procedures followed by root canal treatment $(84 \%)$ and crown preparation with impression procedure $(77.2 \%)$.

Conclusion: Adolescents were highly anxious to surgical and invasive dental procedures. Dentists should reduce their anxiety levels by behavior management techniques before treating them.

Keywords: Dental anxiety, Dental procedures, Adolescents

\section{Introduction}

Dental anxiety determines the frequency of treatment availed and remains a barrier in maintaining oral health ${ }^{[1]}$. Despite of many innovations in dentistry i.e. with the advances in dental materials, treatment plan techniques and increased oral health awareness still there is a significant percentage of people suffer from dental anxiety ${ }^{[2]}$. The etiology of Dental anxiety depends on the age of onset; during adulthood, cause is usually a negative dental experience or due to general anxiety states. In the childhood it is multi factorial likewise due to several interacting factors, personal as well as environmental, contribute to the development of fear and anxiety in a dental care situation or Psychological factors such as shyness and general fearfulness or immaturity ${ }^{[3]}$. Adolescence refers to the period of accelerated biological growth, changes, and social role transitions that bridges the gap from childhood to adulthood [4]. Dentally anxious adolescents because of their avoidant behavior often have poorer dental health ${ }^{[5,6]}$ as they delay dental visits for a prolonged period of time, even after experiencing considerable pain thereby requiring more complex and complicated treatments. Though dental anxiety is seen in children, adolescents and adults but anxiety levels reduces as age advances ${ }^{[7]}$. Thus adults endeavor more cooperation during the procedure while children and adolescents tend to postpone them. Interestingly, this dental anxiety varies with each dental procedure. Hence in this study we would like to know which dental procedure will provoke more anxiety in adolescents and various behavior management strategies can be followed for anxious patients thereby enable the patient's ability to cope with the anticipated anxiety of dental treatment. 
Materials and Methodology

Ethical Approval: This study was approved by the institutional Ethical Committee, Kamineni Institute of Dental Sciences, Narketpally.

Sample Collection: The study population was recruited from the walk in patients of Kamineni Institute of Dental Sciences, Narketpally. A total of 500 members were selected randomly with the inclusion and exclusion criteria within a time period of six months.

\section{Inclusion criteria}

1. Patients within the age group of 15-19 years of age

2. Willingness to participate in the survey

3. Patients with the ability to understand, read, and fill questionnaires.

\section{Exclusion criteria}

1. Patients not willing to participate in the study.

2. Patients with physical and mental disability.

The total sample was divided into two groups based on gender i.e Group I - Male and Group II -Female with 250 members in each group. Anxiety levels were assessed with a custom-made questionnaire formulated in English and local language. The questionnaire consists of queries related to anxiousness for the frequently done dental procedures (Table 1). In the reception area during waiting period, the eligible and willing adolescents received structured questionnaire in a printed form after a brief explanation about the study and its purpose. Filled questionnaires were collected on the same day and the obtained data was tabulated and analyzed statistically.

\section{Results}

The total sample was divided into two Groups- Group I Male and Group II- Female with 250 members in each group. In both Group I (Male) and Group II (Female), it was reported that $4.4 \%$ and $14.8 \%$ of sample population were highly anxious, $14.4 \%$ and $16.4 \%$ were moderately anxious along with $81.2 \%$ and $68.8 \%$ were reported with no anxiety to scaling and polishing procedures respectively. Relating to tooth drilling and restorative procedure it was reported that $11.2 \%$ and $33.2 \%$ were highly anxious, $17.2 \%$ and $18.8 \%$ were moderately anxious with $71.6 \%$ and $48 \%$ were not anxious to this procedures respectively. With crown preparation and impression making procedures, $64.4 \%$ and $77.2 \%$ of sample were highly anxious, $24.4 \%$ and $20.8 \%$ were moderately anxious and $11.2 \%$ and $2 \%$ were not anxious. With regard to root canal treatment procedure it was reported that $70.8 \%$ and $84 \%$ of sample were highly anxious, $22.4 \%$ and $14.4 \%$ were moderately anxious and only $6.8 \%$ and $1.6 \%$ were not anxious to this procedure. It was concluded that $76.4 \%$ males and $89.4 \%$ females were highly anxious, $18.8 \%$ males and $10.8 \%$ females were moderately anxious and only $4.8 \%$ males were not anxious about extraction/ surgical procedure. (Table 2)

\section{Discussion}

Dental anxiety has been cited as the fifth-most common cause of anxiety by Agras et al. ${ }^{[8]}$ Studies have shown that fears and phobias decline with age, which could be attributed to age dependent cerebral deterioration, factors like extinction or habituation, and adaptive resignation toward the inevitable ${ }^{[8,9]}$. There were studies which concluded that adolescents had more anxiety towards dental procedures than adults ${ }^{[2,10-12]}$ so we have conducted this study on adolescents, as most of the dentists treat adolescents as adults during the treatment procedure which resulted in increased anxiety in them and this leads to postponement of visits or sometimes not turning up to clinic ${ }^{[13]}$ As adolescents were in a transition phase between child and adults, we should treat them in such a way that our approach should reduce their anxiety.

In our study it was evident that dental anxiety was seen among all the participants and females were highly anxious to the dental procedures compared to male group and these results are similar to other studies conducted $[2,14,15]$ This difference may be explained by women being more able to express their feelings of fear and reluctant for treatment procedure. In addition, physiological conditions such as social phobia, panic, depression, stress, and fear are more common in females, and dental anxiety may be associated with such emotions ${ }^{[16]}$. In a study conducted by Nascimento et al. ${ }^{[17]}$ it was found that people with previous traumatic dental experiences showed higher levels of dental anxiety and similar results were observed in our study that many of adolescents had a unpleasant dental experience resulted in increased anxiety towards dental procedures.

Present study revealed that extraction, root canal treatment, crown preparation procedures provoked more anxiety in adolescents compared to tooth drilling and scaling procedures and results were similar to other studies conducted $[2,11]$. Knowing about anxious provoking treatment procedure, we can easily reduce their anxiety when the respective treatment procedure was planned. Dentists treating the adolescents should first assess their anxiety, retrain them to reduce the anxiety levels which ultimately instills positive dental attitude.

Table 1: Custom Made Questionnaire

\begin{tabular}{|c|cc|}
\hline S.No & \multicolumn{2}{|c|}{ Questions } \\
\hline $\mathbf{1}$ & \multicolumn{2}{|c|}{ If you were about to have a tooth drilling and restoration, how would you feel? } \\
\hline & a. & Not anxious/mild anxious \\
\hline & b. & Moderate anxious \\
\hline & c. & Extremely anxious \\
\hline $\mathbf{2}$ & \multicolumn{2}{|c|}{ If you were about to have your teeth scaled and polished, how would you feel? } \\
\hline & a. & Not anxious/mild anxious \\
\hline & b. & Moderate anxious \\
\hline & c. & Extremely anxious \\
\hline $\mathbf{3}$ & \multicolumn{2}{|c|}{ If you were about to undergo Root canal treatment, how would you feel? } \\
\hline & a. & Not anxious/mild anxious \\
\hline & b. & Moderate anxious \\
\hline & c. & Extremely anxious \\
& & \\
\end{tabular}




\begin{tabular}{|c|c|}
\hline 4 & If you were about to undergo crown preparation and impression taking, how would you feel? \\
\hline & a. $\quad$ Not anxious/mild anxious \\
\hline & b. Moderate anxious \\
\hline & c. Extremely anxious \\
\hline 5 & If you were about to undergo Extraction/surgical procedure, how would you feel? \\
\hline & a. $\quad$ Not anxious/mild anxious \\
\hline & b. Moderate anxious \\
\hline & c. Extremely anxious \\
\hline
\end{tabular}

Table 2: Anxiety Levels of Adolescents to Dental Procedures

\begin{tabular}{|c|c|c|c|c|c|c|}
\hline \multirow{2}{*}{ Groups } & Anxiety Levels & $\begin{array}{c}\text { Extraction/Surgical } \\
\text { Procedure }\end{array}$ & $\begin{array}{c}\text { Root Canal } \\
\text { Treatment }\end{array}$ & $\begin{array}{c}\text { Crown Preparation } \\
\text { Followed By } \\
\text { Impression }\end{array}$ & $\begin{array}{c}\text { Tooth Drilling } \\
\text { Followed By } \\
\text { Restoration }\end{array}$ & $\begin{array}{c}\text { Scaling and } \\
\text { Polishing }\end{array}$ \\
\hline \multirow{2}{*}{$\begin{array}{c}\text { Group I } \\
\text { (Male) }\end{array}$} & Highly Anxious & $76.4 \%$ & $70.8 \%$ & $64.4 \%$ & $11.2 \%$ & $4.4 \%$ \\
\cline { 2 - 7 } & Moderately Anxious & $18.8 \%$ & $22.4 \%$ & $24.4 \%$ & $17.2 \%$ & $14.4 \%$ \\
\hline \multirow{2}{*}{$\begin{array}{c}\text { Group II } \\
\text { (Female) }\end{array}$} & Not Anxious & $4.8 \%$ & $6.8 \%$ & $11.2 \%$ & $71.6 \%$ & $81.2 \%$ \\
\cline { 2 - 7 } & Moderately Anxious & $89.2 \%$ & $84 \%$ & $77.2 \%$ & $33.2 \%$ & $14.8 \%$ \\
\cline { 2 - 7 } & Not Anxious & $10.8 \%$ & $14.4 \%$ & $20.8 \%$ & $18.8 \%$ & $16.4 \%$ \\
\hline \multirow{2}{*}{} & $0.00 \%$ & $1.6 \%$ & $2 \%$ & $48 \%$ & $68.8 \%$ \\
\hline
\end{tabular}

\section{Conclusion}

Most of the adolescents were highly anxious to the dental procedures such as extraction/ surgical procedures followed by root canal treatment and crown preparation with impression procedure. Many of them were not anxious about tooth drilling with restorative procedure and oral prophylaxis. Hence it is important for the dentist to withdraw the dental anxiousness and emphasize the positive effects of initial phase of treatment.

\section{References}

1. Saatchi M, Abtahi M, Mohammadi G, Mirdamadi M, Binandeh ES. The prevalence of dental anxiety and fear in patients referred to Isfahan Dental School, Iran. Dent Res J (Isfahan) 2015;12:248-53.

2. Sinha E, Rekha R, Nagashree SR. Anxiety of dental treatment among patients visiting primary health centers. J Indian Assoc Public Health Dent 2019;17:235-40.

3. Locker D, Liddell A, Dempster L, Shapiro D. Age of onset of dental anxiety. J Dent Res 1999;78:790-6.

4. Sawyer SM, Azzopardi PS, Wickremarathne D, Patton GC. The age of adolescence. Lancet Child Adolesc Health 2018;2(3):223-8

5. Eitner S, Wichmann M, Paulsen A, Holst S. Dental anxiety - An epidemiological study on its clinical correlation and effects on oral health. J Oral Rehabil 2006;33:588-93.

6. Armfield JM, Slade GD, Spencer AJ. Dental fear and adult oral health in Australia. Community Dent Oral Epidemiol 2009;37:220-30.

7. Folayan MO, Idehen EE, Ojo OO. The modulating effect of culture on the expression of dental anxiety in children: A literature review. Int J Paediatr Dent 2004;14:241-5.

8. Agras S, Sylvester D, Oliveau D. The epidemiology of common fears and phobia. Compr Psychiatry. 1969;10(2):151-156.

9. Locker D, Liddell A, Burman D. Dental fear and anxiety in an older adult population. Community Dent Oral Epidemiol 1991;19:120-4.

10. Mohammed RB, Lalithamma T, Varma DM, Sudhakar $\mathrm{KV}$, Srinivas B, Krishnamraju PV et al. Prevalence of dental anxiety and its relation to age and gender in coastal Andhra (Visakhapatnam) population, India. J Nat Sc Biol Med 2014;5:409-14.

11. Appukuttan D, Subramanian S, Tadepalli A, Damodaran LK. Dental anxiety among adults: An epidemiological study in South India. North Am J Med Sci 2015;7:13-8.

12. Reddy ER, Raju SS, Merum K et al. Postgraduates' Perspective of Pediatric Dental Chair: A Questionnaire Study. Int J Clin Pediatr Dent 2020;13(3):251-254.

13. Fotedar S, Bhardwaj V, Fotedar V. Dental anxiety levels and factors associated with it among patients attending a dental teaching institute in Himachal Pradesh. SRM J Res Dent Sci 2016;7:153-7.

14. Peretz B, Efrat J. Dental anxiety among young adolescent patients in Israel. Int J Paediatr Dent 2000;10:126-32.

15. McGrath $\mathrm{C}$, Bedi R. The association between dental anxiety and oral health-related quality of life in Britain. Community Dent Oral Epidemiol 2004;32:67-72.

16. Arslan S, Erta E, Ülker M. The relationship between dental fear and sociodemographic variables. Erciyes Med J 2011;33:295-300.

17. Do Nascimento DL, da Silva Araújo AC, Gusmão ES, Cimões R. Anxiety and fear of dental treatment among users of public health services. Oral Health Prev Dent 2011;9:329-37. 